\title{
Introduction to Youth Marketing to Digital Natives
}

In this book, I offer new lenses to decode the youth market from the perspective of digital natives and their youth consumption cultures. Whether you are a researcher, a student, a business professional, or a brand manager, you will find in this book novel tools and a new segmentation method that can help you deal effectively with this paradoxical, digital, emotional, ethical, and collaborative youth group.

In line with studies in the marketing field that have examined digital natives, this book aims to deepen the reflection on the world of consumption and the behaviors of different groups of young consumers, whether they are children, tweens, pre-adolescents, adolescents, post-adolescents, or young adults. This approach, which centers on the different stages of the lifecycle from childhood to post-adolescence, is essential as it allows the reader to understand the evolution of these young consumers across different youth cultures in which their purchasing and consumption behaviors are shaped and rooted. The main contribution of this work consists in establishing an in-depth analytical review of existing studies on digital natives' behaviors in the consumption field and how they learn to become full and legitimate consumers and brands' partners. Whether they are French, American, Italian, or Danish, young consumers who belong to the same Western culture constitute a generation of digital natives for whom new technologies and social media platforms represent an integral part of their socialization and consumption activities. The purpose of their consumption is above all symbolic, emotional, and relational, and not purely utilitarian. For digital natives, the consumption of brands is a means that facilitates the integration and conformity of the young person to a particular youth consumption culture. It is through their shared consumption practices and brands that a digital native youth identity is created.

This digital native identity is then constructed and shaped by the codes and norms shared by the members in each youth consumption culture and breaks with previous generations' practices. Beyond a definition delimiting the age group of digital natives, in this book I introduce the idea of consumption practices anchored in a youth culture, which seems, at first glance, to homogenize all digital natives by contrasting them with older generations, such as their parents and the Baby Boomers. Thus, digital natives share an identical 
attraction for the consumption practices and brands adopted by their group. As a result, they participate in the creation of common generational references. Although digital natives are currently a hot topic and the subject of several forums and columns in various magazines for marketing managers, human resources managers, institutions, and educators, to our knowledge no professional and scientific reference has examined digital natives' consumption practices from the perspective of youth cultures. Therefore, to fill this gap in both business and academia and thus enhance our understanding of digital natives, I examine in this book the concept of digital natives by considering a youth-centric approach where consumption practices, as well as the adoption and/or the rejection of brands, are strongly embedded in several interdependent youth cultures that should be decoded to capture the meanings these young consumers assign to brands and their paradoxical behaviors.

Youth Marketing to Digital Natives, therefore, provides the reader with new horizons when it comes to marketing strategies and segmenting the youth market. The book does so by considering a unique and innovative field guide to decode youth norms and codes that businesses can use to promote their brands, implement engaging communication campaigns both online and offline, and create new products and services that are meaningful for digital natives - ones that fit with the different youth consumption cultures they belong to. In this book, I offer an overview of youth consumption cultures and new tools to segment the youth market. I introduce a new segmentation method, called "segmenculture", based on the characteristics of youth cultures, which marketing and brand managers can implement to better target the youth market. Segmenculture is a holistic technique that allows companies to segment the youth market into four major interconnected youth consumption cultures, namely childescence, adonascence, adolescence, and adulescence.

Numerous cases, figures, and tables illustrate each chapter.

This book focuses on a new way of thinking about youth marketing that could be a strategic framework and a tool to help businesses targeting the youth market design and implement successful products, services, and experiences aimed at digital natives. By offering a critical analysis of existing works that examine young consumers' behaviors, the book provides answers through the development of the following themes: who are digital natives, and how should the youth market be segmented? How do these young people become consumers? Why should brands learn more about young consumer socialization and the learning process in youth cultures? How can companies shift from offering products to designing suitable experiences and co-creating with digital natives to create a strong competitive advantage?

In this book, I have combined my professional expertise and my prior work on digital natives and youth consumption cultures in different fields. This book provides an extensive review of the existing knowledge in this field and 
examples. I hope the book will help readers gain an in-depth understanding of the paradoxical behaviors of digital natives shaped by the norms and the codes in different youth consumption cultures. 